\title{
Empirical Study on Forewarning of Urban Sustainable Development
}

\author{
Zhang Wen-jin
}

Business Colleg Hohai University Nanjing, China

\begin{abstract}
A forewarning model was set up to evaluate the process of urban sustainable development based on fuzzy matter element theory. Taking status of Nan tong city from 2005 to 2008 as an example, we set up an index system of forewarning in the process of urban sustainable development in Nan tong and established the forewarning standards, limits and degrees.
\end{abstract}

Index Terms: Fuzzy matter element; city; sustainable development; forewarning model

(C) 2013 Published by MECS Publisher. Selection and/or peer review under responsibility of the International Conference on E-Business System and Education Technology

\section{INTRODUCTION}

The forewarning system of urban sustainable development (SD)is a complicated system combined with society, economy, environment, resources, aims to prevent the city developing deviated from its sustainable route; to foresee the trend and speed of the inverse change to the Sustainable Development; to avoid serious conflicts between urban development and environment protection [1-2]. This essay sets up a forewarning model for the urban sustainable development, bases on the reference to related research, and takes Nantong city as an empirical example.

\section{URBAN SUSTAINABLE DEVELOPMENT FOREWARNING MODEL}

\section{A. The establishment of forewarning standard}

In order to do the research, we divide the forewarning into four degrees, that is no alert, light alert, mid-degree alert, heavy alert, and in the range 0-10 level within the division. For the smaller the more superior type, the correlation between forewarning criteria and indicators range in table1. $S_{1}, S_{2}, S_{3}$ is an indicator of forewarning threshold of the criteria, correspondingly, there are 4 levels index value, which respectively establishes correspondence with index range of indicators standard. Similarly, the index range of the bigger the worse superior type can be concluded [3].

\footnotetext{
* Corresponding author: Shi-xia Zhang

E-mail address: zhangwenjin@yahoo.cn
} 
TABLE I. THE ALERT DEGREE AND INDEX

\begin{tabular}{|c|c|c|c|c|}
\hline Alert degree & No alert & Light alert & Mid-degree alert & Heavy alert \\
\hline Forewarning index & {$[0,2.5)$} & {$[2.5,5)$} & {$[5,7.5)$} & {$[7.5,10)$} \\
\hline Index range & $<S_{3}$ & {$\left[S_{3}, S_{2}\right)$} & {$\left[S_{2}, S_{1}\right)$} & $\geq S_{1}$ \\
\hline
\end{tabular}

\section{B. Standard fuzzy matter-element}

On the basis of determining fuzzy matter-element, combined with forewarning standards, we calculate the standard forewarning indicators of evaluation index, then establish a new standard fuzzy matter-element. concerning the smaller the more superior type of indicators, take $S_{1}, S_{2}, S_{3}$ in table 1 for examples, evaluation index corresponding fuzzy matter-element of the forewarning indicators can be calculated in accordance with the following formula:

No alert: $X_{i j}=2.5+2.5 \times \frac{\left(U_{i j}-S_{3}\right)}{S_{3}} \quad\left(S_{3} \succ U_{i j}\right)$

Light alert: $X_{i j}=5+2.5 \times \frac{\left(U_{i j}-S_{2}\right)}{\left(S_{2}-S_{3}\right)} \quad\left(S_{3} \prec U_{i j} \prec S_{2}\right)$

Mid-degree alert: $X_{i j}=7.5+2.5 \times \frac{\left(U_{i j}-S_{1}\right)}{\left(S_{1}-S_{2}\right)} \quad\left(S_{2} \prec U_{i j} \prec S_{1}\right)$

Heavy alert: $X_{i j}=7.5+2.5 \times \frac{\left(U_{i j}-S_{1}\right)}{S_{1}} \quad\left(S_{1 \prec} U_{i j}\right)$

If $X_{i j}<0$, then the value is 0 ; if $X_{i j}>10$, then the value is $10 . U_{i j}$ is the value of indicators. By the same token, the bigger the more superior type of indicators can be calculated, received the standard fuzzy matter-element as follows:

$$
R_{i j}=\left[\begin{array}{ccccc} 
& M_{1} & M_{2} & \cdots & M_{m} \\
c_{1} & X_{11} & X_{21} & \cdots & X_{m 1} \\
c_{2} & X_{12} & X_{22} & \cdots & X_{m 2} \\
\vdots & \vdots & \vdots & \vdots & \vdots \\
c_{n} & X_{1 n} & X_{2 n} & \cdots & X_{m n}
\end{array}\right]
$$

In the above formula, the $R_{i j}$ represents matter i's $c_{j}$ th character fuzzy matter element, $i=1,2, \ldots, m ; j=1,2, \ldots, n$.

\section{The determining of forewarning index weights}

In this paper, we use analytic hierarchy process (AHP) to determine the relative importance order between the evaluation indexes, thus get the weight of evaluation of index, and prior to normalization in the synthesis, namely:

$$
\sum_{i=1}^{n} w_{i}=1 \quad\left(w_{i} \geq 0, i=1,2, \cdots, n\right)
$$




\section{Comprehensive forewarning model}

A comprehensive forewarning analysis for the SD system is the key method to measure development status of system comprehensively. Based on fuzzy matter-element matrix and the index weight set, weight $\mathrm{n}$-dimensional matter-element, calculate comprehensive forewarning indicators, the calculation model as follows:

$$
\begin{gathered}
I_{i}=W_{j} \times R_{i j}=W_{j} \times\left[\begin{array}{ccccc} 
& M_{1} & M_{2} & \cdots & M_{m} \\
c_{1} & X_{11} & X_{21} & \cdots & M_{m 1} \\
c_{2} & X_{12} & X_{22} & \cdots & M_{m 2} \\
\vdots & \vdots & \cdots & \vdots & \cdots \\
c_{n} & X_{1 n} & X_{2 n} & \cdots & M_{m n}
\end{array}\right] \\
=\left(\sum_{j=1}^{n} W_{j} X_{1 j}, \sum_{j=1}^{n} W_{j} X_{2 j}, \cdots, \sum_{j=1}^{n} W_{j} X_{m j}\right)=\left(I_{1}, I_{2}, \cdots \mathrm{I}_{\mathrm{m}}\right)
\end{gathered}
$$

According to index range corresponding to forewarning level in forewarning standards, judge $m$ one matter's comprehensive forewarning indicators $I_{i}(i=1,2, \ldots, m)$ belongs to the alert degree, then publishing a forewarning report.

\section{SD FOREWARNING EVALUATION OF NANTONG CITY}

\section{A. Forewarning index system}

To establish a forewarning index system (FIS), we must select quantifiable indicators and obtain some statistical data, meanwhile, the change of index has a bigger impact on sustainable development. In this paper, based on the reference to related research, we select 15 evaluations from economics, society, environment three aspects to establish system [4]. The indicator hierarchy is shown in table 2.

\section{B. The determining of forewarning index weights}

According to index hierarchy in table2, based on the relative importance order between the evaluation indexes that determined by specialists, we use AHP to build comparison matrix, then calculate index weight level by level, take consistency tests.

\section{Forewarning standards setting}

Combined with its own characteristics of Nan tong urban development, in accordance with favorable membership degree principle in forewarning reference standards setting, based on reference to related research results, this paper determines the limits of different indexes, results can be seen in table 3 .

\section{Evaluation of forewarning results}

According to above comprehensive forewarning model of fuzzy matter-element, in accordance with forewarning reference standards, combined with indexes from 2005 to 2008 of Nan tong city, we calculate fuzzy forewarning indexes of the bigger the more superior and the smaller the more superior type of indicators respectively, at last come out the fuzzy comprehensive forewarning indexes of Nan tong urban sustainable development (table 4) 
TABLE II. SD FIS OF NAN TONG CITY

\begin{tabular}{|c|c|c|}
\hline $\begin{array}{c}\text { Target } \\
\text { level }\end{array}$ & Module level & Element level \\
\hline \multirow{15}{*}{$\begin{array}{l}\text { FIS } \\
\text { Of } \\
\text { SD } \\
\text { (A) }\end{array}$} & \multirow{6}{*}{$\begin{array}{c}\text { Environmental } \\
\text { Index } \\
\text { (B1) }\end{array}$} & Park green area per capita (D1) \\
\hline & & Green coverage ratio (D2) \\
\hline & & Domestic sewage treatment rate (D3) \\
\hline & & $\begin{array}{l}\text { Compliance rate of industrial } \\
\text { wastewater discharge (D4) }\end{array}$ \\
\hline & & $\begin{array}{l}\text { Comprehensive utilization rate } \\
\text { of solid waste (D5) }\end{array}$ \\
\hline & & The proportion of good air quality days (D6) \\
\hline & \multirow{2}{*}{$\begin{array}{l}\text { Economic } \\
\text { index(B2) }\end{array}$} & Per capita GDP (D7) \\
\hline & & the proportion of tertiary industry in GDP (D8) \\
\hline & \multirow{7}{*}{$\begin{array}{l}\text { Social Index } \\
\text { (B3) }\end{array}$} & Million people have the number of beds (D9) \\
\hline & & Per capita living space (D10) \\
\hline & & $\begin{array}{l}10000 \text { people have public transport } \\
\text { vehicles ( D11) }\end{array}$ \\
\hline & & Per capita road area (D12) \\
\hline & & Per cargo throughput (D13) \\
\hline & & $\begin{array}{l}\text { Million people in the school } \\
\text { number of students (D14) }\end{array}$ \\
\hline & & Population density (D15) \\
\hline
\end{tabular}

TABLE III. REFERENCE STANDARDS AND ALERT DEGREES OF NAN TONG URBAN SD

\begin{tabular}{|c|c|c|c|c|}
\hline Alert degree & $\begin{array}{c}\text { No } \\
\text { alert }\end{array}$ & $\begin{array}{c}\text { Light } \\
\text { alert }\end{array}$ & Mid-degree alert & $\begin{array}{c}\text { Heavy } \\
\text { alert }\end{array}$ \\
\hline $\begin{array}{c}\text { Forewarning index } \\
\text { range }\end{array}$ & {$[0,2.5)$} & {$[2.5,5)$} & {$[5,7.5)$} & {$[7.5,10]$} \\
\hline D1 & $>20$ & {$[20,10)$} & {$[10,5)$} & {$[5,0)$} \\
\hline D2 & $>60$ & {$[60,30)$} & {$[30,20)$} & {$[20,0)$} \\
\hline D3 & $>80$ & {$[80,60)$} & {$[60,30)$} & {$[30,0)$} \\
\hline D4 & 100 & {$[100,80)$} & {$[80,60)$} & {$[60,0)$} \\
\hline D5 & $>90$ & {$[90,70)$} & {$[70,50)$} & {$[50,0)$} \\
\hline D6 & $>90$ & {$[90,80)$} & {$[80,60)$} & {$[100,0)$} \\
\hline D7 & $>50000$ & {$[50000,20000)$} & {$[20000,10000)$} & {$[50,0)$} \\
\hline D8 & $>70$ & {$[70,60)$} & {$[60,50)$} & \\
\hline
\end{tabular}




\begin{tabular}{|c|c|c|c|c|}
\hline Alert degree & $\begin{array}{c}\text { No } \\
\text { alert }\end{array}$ & $\begin{array}{c}\text { Light } \\
\text { alert }\end{array}$ & Mid-degree alert & $\begin{array}{c}\text { Heavy } \\
\text { alert }\end{array}$ \\
\hline $\begin{array}{c}\text { Forewarning index } \\
\text { range }\end{array}$ & {$[0,2.5)$} & {$[2.5,5)$} & {$[5,7.5)$} & {$[7.5,10]$} \\
\hline D9 & $>60$ & {$[60,40)$} & {$[40,20)$} & {$[20,0)$} \\
\hline D10 & $>15$ & {$[15,12)$} & {$[12,6)$} & {$[6,0)$} \\
\hline D11 & $>10$ & {$[10,5)$} & {$[5,3)$} & {$[3,0)$} \\
\hline D12 & $>30$ & {$[30,10)$} & {$[10,8)$} & {$[8,0)$} \\
\hline D13 & $>20000$ & {$[20000,10000)$} & {$[10000,5000)$} & {$[5000,0)$} \\
\hline D14 & $>2000$ & {$[2000,1500)$} & {$[1500,1000)$} & {$[1000,0)$} \\
\hline D15 & $<700$ & {$[700,5000)$} & {$[5000,10000)$} & $>10000$ \\
\hline
\end{tabular}

TABLE IV. THE RESULT OF COMPREHENSIVE EVALUATION OF NAN TONG URBAN SD FOREWARNING

\begin{tabular}{|c|c|c|c|c|}
\hline $\begin{array}{c}\text { Forewarning } \\
\text { index }\end{array}$ & 2005year & 2006 year & 2007 year & 2008 year \\
\hline D1 & 5.60 & 5.35 & 4.93 & 4.65 \\
\hline D2 & 4.04 & 4.03 & 4.02 & 4.00 \\
\hline D3 & 3.10 & 2.49 & 2.45 & 2.68 \\
\hline D4 & 2.69 & 2.60 & 2.53 & 2.26 \\
\hline D5 & 2.36 & 2.39 & 2.33 & 2.73 \\
\hline D6 & 2.95 & 3.00 & 2.88 & 1.52 \\
\hline D7 & 3.60 & 3.12 & 1.83 & 6.19 \\
\hline D8 & 6.62 & 6.37 & 6.25 & 0.00 \\
\hline D9 & 1.78 & 1.92 & 1.80 & 1.95 \\
\hline D10 & 0.15 & 0.10 & 0.00 & 4.13 \\
\hline D11 & 2.45 & 2.43 & 2.15 & 4.20 \\
\hline D12 & 4.70 & 4.40 & 4.31 & 5.33 \\
\hline D13 & 5.84 & 4.90 & 4.42 & 3.53 \\
\hline D14 & 4.51 & 4.74 & 5.02 & 2.89 \\
\hline D15 & 3.49 & 3.51 & 3.52 & Light alert \\
\hline$I_{i}$ & 3.64 & 3.44 & 3.03 & \\
\hline Alert degree & Light alert & Light alert & Light alert & \\
\hline
\end{tabular}

\section{CONCLUSIONS}

As we can see from the calculated outcome of index (table 4), the majority of factors are showing a good development trend, there is no deterioration development trend, but the individual indicator such as population density and the number of students in school per 10000 people are still in mild deterioration. On the whole, the comprehensive forewarning index of Nan tong urban SD from 2005 to 2008 is 3.64, 3.44, 3.03, 2.89, which shows a declining trend. The SD shows a stable and harmonious trend, which means the efforts for harmonious development of social-economic and ecological environment has achieved certain results. However, from the perspective of alert degree, comparing integrated forewarning index to standard forewarning index interval indicates Nan tong urban SD was still in light alert state in the latest four years, which requires, Nan tong should 
raise vigilance and prevent the reverse development, and earnestly implement the scientific concept of development, adhere to the path of sustainable development in order to achieve regional socio-economic development and natural environment co-ordination and a virtuous circle.

\section{References}

[1] Jing Ping, Jia Hai-feng, Xu Bi-xia, "Trend Forecasting and Forewarning Method for Urban Sustainable Development,”Journal of Chongqing Jianzhu University, Vol.30, No.2, pp116-120, 2008.

[2] Shamsul HM, "Environmental Discourse and Sustainable Development: Linkages and Limitations, " Ethic and the Environment, Vol.5, No.1, pp 3-21,2000.

[3] Fu Juan-lin, Qiao Biao, "Ecological Early-warning Model and Its Application in the Process of Urbanization Based on Fuzzy Matter Element Theory," Advances in Earth Science,Vol.23,No.9, pp990995,2008.

[4] Pan Feng, Liang Chuan, "Fuzzy matter-element model for evaluating sustainable utilization of regional water resources,"Advances in Water Science, Vol.14, No.3, pp271-275, 2003. 